\title{
Thinking on Application of Microteaching to Teaching of Information Technology Course
}

\author{
Chen Meng \\ School of Communications, Inner Mongolia University for the Nationalities, Tongliao, 028000, China
}

Keywords: Information technology. Microteaching. Skill. Course Teaching. Education

\begin{abstract}
With improvement in science and technology, teaching of information technology course plays an increasingly important role in education. Under this situation, teachers of information technology course also enlarge researches and innovation about teaching methods and apply various teaching methods widely in order to make students comprehend and master corresponding theoretical knowledge and operational skills of the information technology course better. Microteaching is applied most extensively. In the following content, the author will analyze problems existing in application of microteaching to teaching of the information technology course on the basis of accumulation and summarization of many years' teaching experience. Based on this, corresponding countermeasures are provided.
\end{abstract}

\section{Introduction}

As educational reform deepens, microteaching is accepted by more and more people gradually. Since microteaching has important effect on improvement in students' teaching theoretical level and practical teaching ability, it has been widely applied to teaching skill training up to now. In the following content, the author will target teaching of the information technology course, as well as think about and analyze application of microteaching to teaching of the information technology course.

\section{Introduction to microteaching}

As microteaching is a controllable practical system, the system can make teachers or normal university students focus on a specific teaching behavior or learn tings under a condition with control. Microteaching is a way to train skill comprehensively, systematically and scientifically based on teaching theories, teaching techniques and audio-visual theory and technology.

Microteaching mainly contains content in two aspects, i.e., master-control room and microteaching classroom. The master-control room can control shots and camera shooting holders at any microteaching classroom effectively, monitor and supervise sounds and images at any microteaching classroom and rebroadcast practical situations of a certain microteaching classroom to other classrooms simultaneously to achieve purpose of demonstration by this. In the master-control room, the involved equipment mainly contains supervisory console, computer, monitor, main control computer, VCD and video tape recorder. In a microteaching classroom, some teaching devices like camera and sub-control machine are mainly included. A microteaching classroom can control picture pick-up system in it effectively as well as record images and sounds in the room. With improvement in science and technology, microteaching also obtains corresponding development. As a result, a kind of digital microteaching system appears, which is network system integrating digital live broadcast, microteaching, video on demand (VOD), multimedia editing, multimedia storage as well as production of phonotape and videotape. In the aspect of information records, this system generally takes hard-disk storage method or optical-disk recording. This method is so convenient that people can request broadcasting, view and emulate as well as evaluate teaching activities by optical disk or network whenever and wherever possible.

Effect of microteaching is mainly reflected in the following aspects. Firstly, by effective combination between theory and practice, students' interest in learning can be improved and their 
learning motivation can be aroused. Secondly, prominence is given to key points, and learning objectives are specific. If teaching is carried out with the help of microteaching classroom, the number of students having lessons is small and the needed time is also short. Since training only focuses on one or two teaching skills, trainees can confirm their learning objectives better and pay their attention to key points more effectively. Thirdly, information feedback is timely, visual and vivid. Recording students' behaviors by using modern information technology can help us obtain corresponding feedback information timely and accurately as well as improve efficiency of training practice. Fourthly, it is helpful for students to exert their dominant role. In microteaching, it is clearly specified that students are subjects, instructors play a leading role and training is regarded as a principal line to carry out teaching. This teaching method also provides convenience for cultivation of students' creative thinking.

\section{Problems related to application of microteaching to teaching of the information technology course}

Although microteaching has many advantages and has been widely applied to trainings of various teaching skills, it still has various problems in the process of practice. Such problems affect and hinder teaching quality and efficiency of information technology course to some extent. Hence, the author will study and analyze these problems in the following content.

Firstly, teachers, equipment and credit hours are insufficient. As educational reform deepens and education is popularized, scope of schools' enrollment is larger and larger, and the number of recruited students also increases. In microteaching training, a teacher has to guide a number of students. Under normal conditions, there are only over 30 credit hours for microteaching training in the teaching of information technology teaching. In these credit hours, theoretical courses occupy the majority compared with practical training. Since practical training has fewer credit hours, the number of times when students participate in practical training is small and relative time is little. As a result, skill training usually is superficial, which leads to the situation that practical training fails to meet standards, let along integration and coordination of skills. In addition, equipment used in microteaching is limited and fail to satisfy students' practical demands. According to statistics, most of majors at many Chinese schools establish microteaching practical training courses in the same term at present, which makes the equipment be severely insufficient to some extent. As a result, requirements of practical skill training of each major cannot be satisfied.

Secondly, the boundary between microteaching training goal and teaching objective is vague and microteaching training comes apart from theoretical learning. When microteaching is carried out in teaching of the information technology course, normal university students' teaching skills are cultivated by virtue of classroom teaching objectives of information technology course at middle schools and primary schools. At this time, classroom teaching objectives are methods and teaching skills become objectives. Since it is impossible for students to master their own teaching when they deal with knowledge, microteaching will change into a learning method or a popularizing way of results at this moment rather than a process of students' practical training. As a result, it will cause the situation that goals of teaching skill training cannot be realized. The phenomenon that microteaching comes apart from theoretical learning is reflected by this: learning of information technology teaching theories, pedagogy and psychology, which have been established before microteaching, lacks visual cognition. Such a situation causes a weak link of teaching design before skill training, superficial analyses of teaching objects, teaching methods, teaching content and teaching strategies, and difficulty in improving skill training to a higher level. At the same time, it is difficult to combine theoretical analysis with practical skill training effectively when evaluation is carried out because of constraints resulted from credit hours. Besides, obtained evaluative feedback is not reasonable or scientific enough, so it is impossible to combine practical training with all kinds of problems appearing in theoretical teaching dynamically.

Thirdly, role ambiguity results in distortion of evaluation. In microteaching, there is another important feature, i.e., role play. When microteaching is applied to teaching of the information 
technology course, it is difficult for both teaching and students to enter a real teaching state because they stay in a fictitious environment and are affected by these fictitious situations. As a result, it is impossible to evaluate teachers' skills and teaching behaviors actively, carefully, objectively and positively because there are impacts of psychological factors or other aspects. At last, this causes the situation that evaluation suffers distortion when microteaching is applied to teaching of the information technology course, which reduces efficiency and quality of microteaching training.

Fourthly, educational practice comes apart from practical training related to microteaching and the channel by which teaching feedback information is obtained is interrupted. When students have practice, educational intern students and teachers leading practice usually ignore this and even forget to consolidate and improve training of microteaching practical skills. In traditional teaching, these devices or materials demonstrating teaching stay in a small scope of teachers' control. Teachers' action modeling and words tend to form a harmonious and uniform picture easily. At the same time, teachers' sight can be based on the foregoing behaviors to control students' observation and reflection. Nevertheless, when microteaching is applied to practical teaching of information technology course, positions of experimental console and screen are far away. Meanwhile, in the process in which a lesson is give, teachers who give instructions usually focus on operation panel only and ignore operating results shown on the screen easily when they operate and demonstrate related content, which makes them cannot observe or master students' learning behaviors in teaching process conveniently.

\section{Related strategies about application of microteaching to teaching of the information technology course}

\section{Teaching design}

Compared with other kinds of teaching, microteaching is short. Thus, being different from other classroom designs of teaching, teaching design and analysis must not be implemented according to macro-structural elements when teaching is carried out. On the contrary, a fact, a method, a concept or a principle should be regarded as a set of decomposition courses to perform design, modern education theory is used as guidance, and practical training is implemented for students by virtue of modern educational technology and approaches.

Basic pattern of microteaching is preparation, trial teaching, preparation and trial teaching. When microteaching is applied to teaching of the information technology course, it is essential to follow theories to learn things and achieve the following work, such as making teaching plans, understanding teaching objectives and teaching content, writing teaching plans, role play and feedback evaluation, in order to decompose teaching process into corresponding small teaching skills. At the same time, perform scientific classification, individual training and repeated training to finish overall teaching objectives. In addition, teachers should use various kinds of existing modern audiovisual equipment and techniques to give feedback about information reasonably and scientifically in teaching to make trainees observe, adjust, analyze and evaluate their activities directly and improve efficiency and quality of teaching training further.

\section{Implementation strategies}

Firstly, increase input into practical training equipment of microteaching and add credit hours. In order to make students master knowledge better, increase their chances to take microteaching practical training and enable them to have enough time to watch and amend their own teaching skills, we must increase input into practical training equipment of microteaching and add credit hours first. At the same time, schools should open laboratories appropriately and reasonably in extracurricular time in order that students can make full use of their spare time to do experiments and operations. In doing so, they can be more familiar with specific operating methods of equipment. Then, rate of equipment utilization and microteaching efficiency can be improved further.

Secondly, enhance theoretical learning and strengthen the relationship between microteaching and educational practice. Basic theoretical knowledge of microteaching is indispensable theoretical support for implementation of microteaching. Thus, we must pay much attention to it. First of all, we 
should enhance learning and comprehension of knowledge related to teaching design theories and educational psychology, refine and decompose all teaching skills and use methods, for instance, demonstration, to implement teaching. This can not only make students understand and master basic theories and real connotation of microteaching better but also arouse students' initiative and enthusiasm for learning. Next, in the process in which microteaching is applied, teachers should correctly guide students to integrate teaching behaviors in their mind with explicit teaching operation and expression effectively in order that students can control their own teaching behaviors more effectively. In microteaching, educational practice is an essential link. In order to make students apply the teaching skills that they have mastered in microteaching training to the whole teaching actively effectively as soon as possible, microteaching recall activities can be developed to make students recall all skills they have learned and train their teaching skills. When teaching practice is carried out, teachers should combine all practice groups effectively and invite other teachers to evaluate the whole link and teaching skills of intern students. In this way, students' teaching skills can be consolidated and level of their skills can be improved to some extent.

Thirdly, evaluate students' skills reasonably and scientifically. Firstly of all, perform self-analysis of role play and correct students' consciousness and attitudes towards assessment. In detail, teaches may organize students to discuss all kinds of problems that they meet in practice, as well as encourage and ask students to put forward their own ideas and suggestions boldly. Then, when evaluation is carried out, teachers should combine features of teaching of the information technology course, make specific and reasonable evaluation system and methods clear and guide students to perform evaluation reasonably and scientifically in order to prevent the relationship among students from being affected by dissension in the process of discussion. Finally, students combine with suggestions proposed by teachers and comments given by other classmates to improve their training methods reasonably in order that they can make full preparation for future work. Besides, it is essential to master information technology course comprehensively, systematically and skillfully, and use operating platform and classroom language reasonably.

Fourthly, pay attention to dealing with the relationship between entirety and part, and optimize effect of skill training. In the process of microteaching, teaching content that cannot be mastered easily and complicated teaching process should be divided into single skill training based on overall principles. After single training has been finished, combine all skills effectively. In doing so, more ideal teaching effect can be achieved.

\section{Conclusion}

To sum up, when microteaching is applied to teaching of information technology course, we should clearly understand teaching content and teaching goals first and then perform emulation, demonstration, analyses and discussion as well as compile corresponding teaching plans. After finishing role play and tasks of microteaching practice, carry out evaluative feedback and alter teaching plans. Besides, it is important to combine educational practice with skill training effectively in teaching. In doing so, we can achieve more satisfying teaching effect.

\section{References}

[1] Liu Jianguo, Li Ting and Chen Xiaojing. Primary Investigation on Innovative Microteaching Mode of Information Technology, Journal of Changchun Normal University (Natural Science Edition), 2011,30(6):106-108.

[2] Ye Guping and Wang Weidong. A Research on Network Digital Microteaching System Based on Cloud Computing, Modern Educational Technology, 2013,23(7):67-71.

[3] Zhang Jingchuan. A Research on Teaching Skill Training under the Environment of Information Technology - Application of Microteaching Method, Software Guide, 2013,(8):184-186. 
[4] Yang Jianliang. Design of Network-based Digital Microteaching System, Chinese Educational Informationization · Higher Education and Vocational Education, 2010,(6):35-37.

[5] Ni Sheng. Microteaching Resource Management Based on Web and Design of Evaluation System, Modern Educational Technology, 2011,21(2):129-131.

[6] Zhang Ying, Shen Hongliang and Chu Zhifei. Practical Attempt about Application of Microteaching Mode to Operating Technique Teaching of Clinical Practice, Medical Information, 2012,25(10):11-12.

[7] Xu Jianzhi, Chen Xiaohui and Wang Yongmin et al. Discussion on Cases about Digital Microteaching System and Existing Problems, Computer and Telecommunications, 2009,(8):18-20.

[8] Zhang Shiying, Chen Min and Tang Xinhui. Construction and Application of Multifunctional Training Room Based on Microteaching System, Laboratory Research and Exploration, 2012,31(3):166-170,217. 